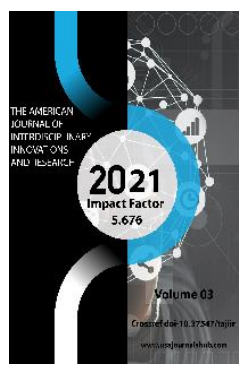

\title{
Case Study Method For Teaching Russian Language As A Foreigner
}

\author{
Yusupova Nigora Muxamedjanovna \\ Lecturer, Department Of Uzbek Language And Literature, Tashkent State Technical University \\ Named After I. Karimov, Uzbekistan
}

Copyright: Original content from this work may be used under the terms of the creative commons attributes 4.0 licence.

\section{ABSTRACT}

The article substantiates the importance of teaching Russian language to foreign students using the case study method. Now there is a lot of talk about the need to strengthen the communicative component when teaching Russian as a foreign language. This goal can be facilitated by the use of cases in classes with foreigners. The classic case contributes to the development of skills for making an independent decision, the purpose of working with a case in an audience with foreigners is different - a communicative workshop. The article lists the topics on which cases can be offered to foreigners, and presents the development of one of the cases as an example of the concept we propose.

\section{KEYWORDS}

Case studies, Russian as a foreign language, communication, interactive teaching methods.

\section{INTRODUCTION}

The case study method is a method of active analysis of a problem situation, based on learning by solving specific situational problems. The essence of the case study method: students, divided into groups, must analyze the situation and work out a practical solution; the end of the process - the evaluation of the proposed algorithms and 
their discussion in the framework of a general discussion in the context of the problem posed.

For the first time the case method was applied in the educational process in 1870 at the Harvard Law School by the dean of the Faculty of Law, professor of law Christopher Columbus Langdell. "Using the Socratic method (question - answer), developing the trial and error method, he invited students to work with primary sources (court cases, decisions of the appellate court, etc.), and then draw their own conclusions, present their own interpretations and analysis. Langdell's approach differed sharply from traditional teaching (lectures, seminars) by inductive empiricism and was met with tremendous resistance" $[1$, p. 43]. Despite this, in the first three years, the method was established not only at Harvard. Its uniqueness and effectiveness have been appreciated in six other law schools. Instead of traditional lectures, the students looked at and discussed real legal situations that happened in life. Students prepared for classes in advance by studying folders with real documents. This experience exceeded all expectations and was soon recognized as promising. And its implementation began at Harvard University also in the teaching of medicine and business administration.

\section{MATERIALS AND METHODS}

In Soviet didactics, the case was introduced into the educational process by S.T. Shatsky. But in the 30s, this method was banned. The case returned to Russian education in the gos of the twentieth century and became a fairly popular method. As usually happens, the initial idea acquires new meanings, various options and variations appear, increasingly moving away from the original source. Sometimes it is even difficult to understand why the author of the article writes that he uses case studies: his "cases" are so far from the method developed at Harvard. For example, in the article by M.A. Shutyak, tasks are proposed for foreigners studying Russian, the solution of which requires one correct answer, which contradicts the idea of alternative solutions to the proposed life situation [6]. I must say that the tasks themselves are quite interesting. But what does the case have to do with it? In the article by $M$. V. Konovalova, for example, we can observe a contradiction in the presentation of the theory of case learning and the presented developments. "The model is being developed according to certain rules of a specific situation that occurred in real life," says the article [3, p. 6]. In practice, situations are proposed from literary works that have nothing to do with life.

We offer case studies in the classical sense, where the case presents a life problem situation that students need to solve based on existing knowledge, practical experience and intuition. Since any situation has several solutions, there is a discussion of all possible solutions.

The use of case studies is limited in the lessons of Russian as a native language, since the features of the material (spelling and punctuation, grammar and phonetics) suggest, as a rule, one correct answer when solving a problem situation. But when teaching Russian as a foreign language, the case study can be used quite widely.

When solving the problematic problem of the case, the ability to listen is developed, to take into account an alternative point of view and to express one's own, to orientate and adapt to a new language environment for foreigners, to remain face to face with real situations. With the help of this method, quickly adaptable foreign students have the opportunity to be ready to work in a team, to find the most rational solution to the task. Analytical and communication skills are formed and developed; research activities are carried out. It is natural to use situational analysis both for teaching professional and everyday communication. 
Cases can be offered in different forms: resources from the Internet and periodicals, articles from encyclopedias, announcements, financial and economic reports, letters, materials from archives, and even in the form of audio and video formats. The main thing is that the information presented in the case has a clear and accessible structure with acceptable and understandable definitions and accurate data.

There are a number of works devoted to the use of case studies in a foreign audience, with the concept of which we agree, for example, $\mathrm{K}$. $\mathrm{Yu}$. Gairbekova writes that the purpose of cases in teaching RFL is to contribute to the formation of communicative and socio-cultural knowledge of students studying Russian as a foreign language, in the process of creating different situations of communication, extremely close to real [2, p. 40].

\section{RESULT AND DISCUSSION}

I.A. Oskolskaya suggests that when choosing a topic for a training "case", you should adhere to the following rules:

1. The specifics of the topic should be simple, that is, the study of the sphere / industry should not take more resources than the study of the tasks.

2. The topic must be public, ie. the industry data or company statistics you are looking for are freely available.

3. The topic should be "real", the student should not be distracted by "fantasy" in the process of solving [5, p. 79].

In choosing a topic, an individual approach is important and what is relevant for this group of students. It is necessary to focus on the characteristics of this team: age, country, nationality. Information is selected that is relevant and acceptable for a given, specific group of students, taking into account national traditions and peculiarities of mentality. For example, with students from the USA, Europe, we can communicate on topics of sexual minorities, extramarital affairs, but with Muslim students this conversation is not desirable. It is important to determine the nature of the relationship between the participants. How often do they communicate with each other? What kind of emotional climate has formed between them? We advise to conduct K-studies in groups where the first stage of communication has already been overcome. Otherwise, the distances inherent in unfamiliar people will not allow individuality to manifest openly. And communication will be limited. It should be remembered that the main goal of the case study method in RCT is communication.

There are different methods of carrying out the case, for example, according to L.V. Lezhnina, Z. Yu. Yuldashev [4; 7]. In our work, we took the stages of carrying out the case according to L.V. Lezhnina. This outline is most suitable for conducting a discussion between students who have previously communicated. The division into micro-groups in a familiar environment will be perceived by students naturally and will not create problems in the discussion of a given topic, which will smoothly transfer the conversation from a small circle to a general discussion.

Stages of carrying out the case according to L.V. Lezhnina:

1. Self-acquaintance of the student with the content of the case.

2. A survey on understanding the content of the case.

3. Division by the teacher of students into micro-groups (4-6 people).

4. Discussion of the content of the case in micro-groups.

5. Presentation of group decisions by one of its representatives.

6. Presentation of the decision of the groups as a whole.

7. General discussion and discussion of the solutions obtained. 
8. Generalization of the obtained results and acquired knowledge.

Structure of work in the classroom:

1. Word of the teacher; formulation of the problem.

2. If necessary, the distribution of students in small groups of 4-6 people each).

3. Organization of work in small groups, identification of speakers.

4. Organization of presentation of solutions in small groups.

5. Organization of general discussion.

6. Summarizing presentation of the teacher.

7. Reflection.

When conducting a discussion in an environment unfamiliar to students, where students communicate with each other for the first time, we recommend the stages of carrying out the case according to Z. Yu. Yuldashev [7, p. 20].

\section{CONCLUSION}

In this case, the combination of traditional and interactive methods can give a good result both in the application of knowledge and practical skills, and in the formation of a scale of moral values among students, which is an important factor in fostering a harmonious personality and improving interethnic relations. During approbation at our meetings, intercultural communication was valuable - it is verbal and non-verbal communication between speakers of different languages and cultures.

\section{REFERENCES}

1. Adonina N.P. Case studies: history and modernity // Higher education today. 2012. No. 11. P. 43-48.

2. Gairbekova K. Yu. Game interactive technologies as a teaching tool RCT // Reflection. 2018. No. 5. P. 39-43.

3. Konovalova M.V. Interactive learning at the lessons of the Russian language and literature // Russian language and literature. Everything for the teacher! 2016.

No. 2. P. 2-12.

4. Lezhnina L.V. Case-method in teaching educational psychologists: scientific and methodological aspect // Science and school. 2008. No. 5. P. 68-70.

5. Oskolskaya I. A. Active introduction of case study technology in the process of teaching a foreign language to students of non-linguistic specialties. Science. 2016. No. 3-2 (15). S. 77-82.

6. Shutyak M.A. Case-method at the lessons of Russian as a foreign and non-native language // Fifth floor. 2017. No. 3. P. 25-29.

7. Yuldashev Z. Yu., Bobokhuzhaev Sh. I. Innovative teaching methods: features of the case study of the teaching method and ways of its practical use. Tashkent: iQtiSOdMOliYa, $2006.88 \mathrm{p}$. 